\title{
Factors influencing decision making for healthcare services outsourcing: A review and Delphi study
}

\author{
Zahra Kavosi ${ }^{1}$, Hamed Rahimi ${ }^{2}$, Saeideh Khanian*3, Payam Farhadi ${ }^{4}$, Erfan Kharazmi ${ }^{1}$ \\ Received: 2 Feb 2017 \\ Published: 5 Jul 2018
}

\begin{abstract}
Background: Outsourcing is considered as one of the tools for organizational development and promotion of productivity by managers. In recent years, outsourcing of healthcare services has become significant. The aim of this study was to identify the most important factors influencing the decision making of outsourcing healthcare services.

Methods: This study is a combined study. First, the literature was examined to identify the factors influencing decision making for outsourcing. Then, with the aim of consensus on the most important factors affecting the decision making of outsourcing in health services, the panel of experts and Delphi technique were used. Sampling was purposeful.

Results: In the selected articles, a total of 180 factors were extracted. The members of the panel of experts from these 180 factors selected 29 sub-factors in the form of six main factors: strategy, quality, management, technology, performance feature, and economy, as the most important factors affecting the outsourcing of services. Finally, the results of Delphi showed that 22 sub-factors were more important in outsourcing decision making at healthcare services.

Conclusion: The study showed that the decision making to outsource health services is a complex and multi-criteria decision. Therefore, when deciding to outsource healthcare services, attention should be paid to various factors, such as strategy, quality, management, technology, and economics.
\end{abstract}

Keywords: Outsourcing, Health services, Management, Decision making, Quality, Delphi

Copyright $₫$ Iran University of Medical Sciences

Cite this article as: Kavosi Z, Rahimi H, Khanian S, Farhadi P, Kharazmi E. Factors influencing decision making for healthcare services outsourcing: A review and Delphi study. Med J Islam Repub Iran. 2018 (5 Jul);32:56. https://doi.org/10.14196/mjiri.32.56

\section{Introduction}

The ultimate goal of the healthcare system in each country is to promote the health in people so they can have a healthy life style and participate in the economic and social activities (1). The complexity of the health sectors, the competitive economy of healthcare services, and the need for providing high-quality services have led health organizations to adopt new managerial approaches. Meanwhile, one of the most effective tools that can be considered as an improvement strategy is the organizational restructuring, in particular, the miniaturization and reduction of government ownership. One of the most common interventions in this area is the outsourcing of services (2).

In recent years, outsourcing has been considered by

Corresponding author: Saeideh Khanian, khanian_s@yahoo.com

1. Health Human Resources Research Center, School of Management \& Information Sciences, Shiraz University of Medical Sciences, Shiraz, Iran.

2. Health Services Management Research Center, Institute for Futures Studies in Health, Kerman University of medical sciences, Kerman, Iran.

3. School of Management \& Information Sciences, Shiraz University of Medical Sciences, Shiraz, Iran.

4. Management Department, Zand higher Education Institute, Shiraz, Iran. managers as one of the tools for organizational development and productivity enhancement (3). Outreaching is an integral part of healthcare system reforms, which, by providing a managerial and supervisory tool, leads to improved performance and increased accountability $(4,5)$. Outsourcing is the mechanism of assigning some of the central or non-operational activities of the organization to its supplier outside the organization (6). There are many reasons to outsource services, including reducing costs, increasing efficiency, focusing on core processes, improving skills, reducing service delivery time and increasing competitive advantage (6-8).

In recent years, outsourcing of health services has be-

\section{$\uparrow$ What is "already known" in this topic:}

The number of outsourcing contracts continues to rise. Outsourcing is one of the strategic tools in healthcare administrations for cost saving and quality improvement. The outsourcing decision is complex with many factors involved.

\section{$\rightarrow$ What this article adds:}

This study identified the key factors affecting decision making on outsourcing services in Iran's health system for the first time, which can help to make the right decision for outsourcing health services in Iran and other countries. 
come significant. Currently, Nordic countries, United States, United Kingdom, Canada, New Zealand and Australia are leading in the field of outsourced healthcare services $(2,9,10)$. While outsourcing of non-clinical services has been widely succeeded, the use of this strategy has been accompanied by some risks for clinical services (7). Although the health organizations interested in expanded outsourcing to clinical services (11), some studies have shown a lack of willingness to outsource of clinical services. For example, the results of the Hsiao study in Taiwan showed that less than $3 \%$ of the nutrition, pharmacy, and nursing sectors were assigned to the private sector. These results indicate that Taiwan's hospitals are still hesitant to outsources (12).

Iran's healthcare system has also outsourced some of their services to the non-governmental clinical institutions and in this regard, studies have been done (7). The results of the Tourani et al. illustrated that outsourcing in educational hospital pharmacy has reduced the manpower costs and increased in customer satisfaction (13). However, research's findings of Mousavi et al. showed that the outsourcing has a negative impact on patients' satisfaction and length of their waiting time (14). Karimi et al. found that in the clinical area, the highest outsourcing rates were physiotherapy, radiology, and ultrasound services. Between logistic and administrative, facility engineering maintenance and housekeeping were among the highest rate of outsourced (15).

According to various studies, one of the main reasons for the failure of outsourcing projects is adopting wrong decisions in applying the strategy. Many executives use the outsourcing strategy as a solution without properly recognizing the available status, which ultimately leads to the failure of this process (16). Therefore, decision making for outsourcing is considered as a vital management process. The outsourcing decision is complex with many factors involved. Thus different researchers have emphasized various factors (17-20). Before taking any outsourcing action, effective decision-making criteria must be identified $(16,18)$.

In Iran, Ministry of Health and Medical Education (MOHME) is responsible for governance, policy-making, planning, financing and guiding programs at the national level. At the provincial level, the Universities of Medical Sciences and Health Services (UMSHS) are the most significant government organization that provide people with health services and meeting their demands. At the township and rural level, a District Health Network, consist of a district health center, urban and rural health centers, health posts and health houses provide health services to the people. Beside the UMSHS, some of the services are provided by insurance companies and Social Welfare Organization's provincial and district units. The private health sector plays a significant role in health care provision in Iran. The Private health sector in Iran primarily concentrated on secondary and tertiary health care in urban areas $(21,22)$. Therefore, this study was conducted with the goal of identifying the most important criteria affecting decision making on outsourcing services in Iran's health system.

\section{Methods}

This study is a combined study. First, the literature was reviewed to identify the effective criteria on decision making for outsourcing. Then, with the aim of consensus on the most important criteria affecting the decision making of outsourcing the health system, the panel of experts and Delphi technique were used.

Literature review: The literature review was conducted to identify relevant studies and searching in electronic databases (PubMed, springer, science direct, ProQuest, google scholar and Sid) from 2005 up in both Persian and English. The appropriate combination of following keywords was used to search: Outsourcing decision factors", "Outsourcing decision criteria", "Outsourcing decision determinants" and "Factors influencing outsourcing decision".

With search, 15 papers were selected (12 English and 3 Persian). Then, the criteria influencing the decision making on outsourcing were extracted from these papers, and subsequently, these criteria examined by the panel of experts.

Experts' panel: The purpose of the panel of experts was to select the most important criteria for decision making for outsourcing healthcare services. The panel of experts was composed of 8 members including 3 faculty members of health services management, 3 hospital managers and 2 researchers in the field of outsourcing. Before holding the panel, a list of factors collected and the purpose of the panel was sent to them. By organizing the panel of experts, the most important criteria for outsourcing services were selected. These factors were categorized in the form of criteria and sub-criteria. Then Delphi technique was used to reach an agreement on these factors.

Delphi: Delphi technique is one of the methods for reaching an agreement among experts. In this technique, experts share their opinions anonymously with other experts over the course of several rounds in order to reach consensus $(23,24)$. In this study, the criteria selected through Delphi technique were evaluated to establish an agreement on the results of the panel of experts.

The target group of this study was the pundits and persons involved in the field of healthcare service outsourcing. The criteria for choosing contributors are: (1) Ph.D. or MA in health management and health economy, (2) at least 5 years of hospital management experience, (3) having an occupation in managing support services, managing contracts affairs, managing legal affairs, managing treatment economy, managing treatment monitor, (4) at least 5 years of work experience related to contract matters. Also, the unwillingness to continue to be present in the research was considered as a criterion for withdrawal from the study.

Considering that sampling was purposive in this study, they initially negotiated with 25 specialists who had the criteria for entering the study. Eventually, 20 of them announced their readiness. In order to guarantee anonymity, each participant was given a dedicated code. Participants include hospital managers, coordinators of contract affairs in hospitals, professors of health management and health economy field, contract law experts, and university staff 
managers (including support service management, management of contract affairs, legal affairs management, health economy management, and treatment monitoring management). In this study, the Delphi process included two rounds.

First round: The purpose of the first round was to determine the importance of the criteria and sub-criteria identified in the panel of experts. Data was collected using a checklist tool. In order to measure the significance of the sub-criteria, the 9 ranks Likert range (low importance (13 ), medium (4-6), and important (7-9)) were used. In this round, experts were asked to list their proposed criteria, which added in the next round. For completing the checklist, 2 weeks were given to provide answers. For the analysis of the first round data, the agreement level was considered as $70 \%$. In this way, the sub-criteria, evaluated as less important by over $70 \%$ of the participants, were excluded from the study, and those evaluated as important comprised more than $70 \%$ of participants. Those subcriteria that did not reach an agreement over $70 \%$ were included in the second round. If all sub-criteria of a criterion were excluded, this criterion was also eliminated.

Second round: The goal of the second round was agreement on the residual sub-criteria. In this round, in order to make the appropriate decision, the average score of the sub-criteria in the previous round and the score of each expert were presented (the score of each expert was sent to himself). The analysis of the second round data was similar to the first round. Due to reaching the agreement, there was no need for a third round.

\section{Results}

In the selected articles, a total of 180 factors were extracted. The demographic data of the selected studies and the factors extracted are given in Table 1.

The members of the experts' panel selected 29 subcriteria from the 180 factor identified in the literature in the form of six main criteria: strategy, quality, management, technology, functional characteristics, and economics, as the most important criteria for the outsourcing of services. The results of the experts' panel showed that the factors of strategy, management, and economics have the most sub-criteria in outsourcing decision-making (Table 2).

In the first round of Delphi, 29 sub-criteria from expert panel were listed. According to the participants' viewpoint, 2 sub-criteria excluded and four sub-criteria were also selected in this round. Afterward, the results of first round returned to the participants. In the second round, 5 sub-criteria were excluded from the study as well. Due to the elimination of all sub-criteria of performance characteristics, this factor was excluded. Thus, the results of the

Table 1. Extracted information on studies and effective criteria on outsourcing of healthcare services

\begin{tabular}{|c|c|c|c|}
\hline Authors (Year) & Place & Factor & Sub-Factor \\
\hline $\begin{array}{l}\text { Dawne Lamminmaki } \\
\text { (2010) }\end{array}$ & Australia & None & $\begin{array}{l}\text { Core activities, Flexibility, Specialization, Compatible culture, Trust, Capital } \\
\text { outlay avoidance, Fast expansion facilitation, competitor outsourcing emulation }\end{array}$ \\
\hline \multirow[t]{5}{*}{ Chinyao Low (2012) } & Taiwan & System function & $\begin{array}{l}\text { Usefulness, Ease of use, Accuracy, Tangibles Programming Languages, Relia- } \\
\text { bility, Security/Privacy }\end{array}$ \\
\hline & & Service Quality & $\begin{array}{l}\text { System update medical consult, Maintain service, Customer satisfy, Education } \\
\text { training, Specialization }\end{array}$ \\
\hline & & Integration & Compatibility, Logical structure, Flexible, Customization, Interaction \\
\hline & & Economics & Setup cost, Maintain cost, reputation \\
\hline & & professionalism & Innovation, Experience \\
\hline \multirow[t]{4}{*}{ Saeed Tajdini (2012) } & Iran & Strategic & Core business, Flexibility, Image \\
\hline & & Economical & Cost reduction, Economy of scale, Growth \\
\hline & & Technical & Skill, Management of operational process, New product \\
\hline & & Geo-political & Distance, Political issues, Language barriers \\
\hline Jian-Jun Wang (2008) & China & None & Strategy, Economics, Environment, Risk, Quality \\
\hline Niskanen Salla (2013) & & None & Cost, Strategic, Function characteristics, Environment \\
\hline \multirow[t]{5}{*}{ Joan Rhodes (2014) } & Berlin & Cost & $\begin{array}{l}\text { Lower total cost, Cost reduction, Cost control/reduce operating cost, Improve } \\
\text { the efficiency of operations }\end{array}$ \\
\hline & & Focus & $\begin{array}{l}\text { Allow resources to focus on core competencies, Release resources for other } \\
\text { business }\end{array}$ \\
\hline & & Quality & $\begin{array}{l}\text { Improve conformance quality, Prompt resolution of customer com- } \\
\text { plaints/inquiries }\end{array}$ \\
\hline & & Flexibility & Increase volume flexibility, Lack of capacity, Ability to adjust deliverables \\
\hline & & innovativeness & $\begin{array}{l}\text { Access to specific labor and/or technology expertise, Supplier innovation capa- } \\
\text { bilities, Lower development cost }\end{array}$ \\
\hline \multirow[t]{6}{*}{ Jens Dibbern (2012) } & German & effectiveness & Strategic Benefits, Services Quality, Resources and Skills \\
\hline & and Unit- & Efficiency & Production Costs, Transaction Costs \\
\hline & ed States & $\begin{array}{l}\text { Environmental forces } \\
\text { and Constraints }\end{array}$ & Industry Regulation, Decision Power and Politics \\
\hline & & $\begin{array}{l}\text { National and Industry } \\
\text { Characteristics }\end{array}$ & Country of Origin, Public versus private \\
\hline & & $\begin{array}{l}\text { Organizational Charac- } \\
\text { teristics }\end{array}$ & Financial Situation, Strategic Orientation, Slack Resources \\
\hline & & $\begin{array}{l}\text { Transactional Character- } \\
\text { istics }\end{array}$ & Asset Specificity, Uncertainty, resource Gaps \\
\hline Tibor Kremic (2006) & USA & None & Strategy, cost, function characteristics, environment \\
\hline Edward Muchai (2012) & Kenya & None & $\begin{array}{l}\text { Business strategy, transaction cost, organizational size, lack of technical capaci- } \\
\text { ty, flexibility to market forces of demand and supply }\end{array}$ \\
\hline $\begin{array}{l}\text { Phillip Mollo Oduk } \\
\text { (2013) }\end{array}$ & Kenya & None & Strategic plan, quality improvement, production cost \\
\hline
\end{tabular}




\begin{tabular}{|c|c|c|c|}
\hline Table 1. Cntd & & & \\
\hline \multirow[t]{6}{*}{$\begin{array}{l}\text { Ahmed abduraba Al- } \\
\text { Nehmi (2009) }\end{array}$} & \multirow[t]{6}{*}{ Saudi Arabia } & Strategic & $\begin{array}{l}\text { Focus on core activities, Freeing resources for core activities, Access } \\
\text { to World-Class capabilities, Accelerate re-engineering benefits, Risk } \\
\text { sharing with contractors, Improve flexibility to the changing market } \\
\text { dynamics, Strategic alliance with contractors, Regulations governing } \\
\text { the outsourcing practices }\end{array}$ \\
\hline & & Management & $\begin{array}{l}\text { Save the management time, Reduce the management load, Need for } \\
\text { specialized management, Increase the speed of implementation, Func- } \\
\text { tion difficult to manage, Safety management, Consolidation or Decen- } \\
\text { tralization }\end{array}$ \\
\hline & & Technological & $\begin{array}{l}\text { Achieve flexibility with changing technology, Initiate innovative ideas } \\
\text { and techniques, Improve the technology for competitive advantage, } \\
\text { Technology requirements, Uncertainty, Need for specialized expertise, } \\
\text { Acquire new skills or technical knowledge }\end{array}$ \\
\hline & & Economic & $\begin{array}{l}\text { Save the overall cost, Reduce the labor and operating cost, Make the } \\
\text { fixed costs into variable costs, Improve the cash flow, Cash infusion } \\
\text { Make capital funds more available for core activities, Increase the } \\
\text { economic efficiency }\end{array}$ \\
\hline & & Quality & $\begin{array}{l}\text { Improve service quality, Improve quality requirements, Procure higher } \\
\text { reliability and competency }\end{array}$ \\
\hline & & Function characteristics & $\begin{array}{l}\text { Complexity of function, Function integration and structure, Lack of } \\
\text { spare parts, Function difficult to control, Lack of equipment/tools } \\
\text { availability }\end{array}$ \\
\hline \multirow{7}{*}{$\begin{array}{l}\text { Magiswary Dorasamy } \\
(2010)\end{array}$} & \multirow[t]{7}{*}{ Selangor } & Costs & Organizational costs, production costs \\
\hline & & Resources & $\begin{array}{l}\text { Assets, Organizational characteristic, Processes, Aptitudes, Infor- } \\
\text { mation employees }\end{array}$ \\
\hline & & Competencies & Knowledge, Skills capabilities, Know-how \\
\hline & & Operation management & Focus on core functions, Better management, Enhanced control \\
\hline & & Risk of outsourcing & $\begin{array}{l}\text { Loss of confidential data, Owner responsibility, Changes in suppliers, } \\
\text { Supplier failure }\end{array}$ \\
\hline & & Firm size & Large, Small \\
\hline & & Types of industry & Manufacturing, Non-manufacturing \\
\hline \multirow[t]{3}{*}{ Ghazizadeh fard (2011) } & \multirow[t]{3}{*}{ Iran (Tehran) } & Services & $\begin{array}{l}\text { Quality, Cost, Specialize skills, Flexibility, Specialized equipment, } \\
\text { Possible to ensure }\end{array}$ \\
\hline & & Strategic & Focus on core function, Reduce the management load \\
\hline & & Environmental & $\begin{array}{l}\text { Governmental regulations, Access to secure information, dependence } \\
\text { on supplier }\end{array}$ \\
\hline \multirow[t]{2}{*}{$\begin{array}{l}\text { Yosef Mohammed } \\
\text { Karimi } \\
(2012)\end{array}$} & \multirow[t]{2}{*}{ Iran (Bukan) } & $\begin{array}{c}\text { Internal Organizational } \\
\text { Factors }\end{array}$ & $\begin{array}{l}\text { Reduce the cost of the within organization, Improve organizational } \\
\text { performance, Increase flexibility, Focus to core function, Increase } \\
\text { capacity of using internal resources, Reduce overhead costs, Building } \\
\text { a culture on Organizational Creativity, Lack of required skills in or- } \\
\text { ganization, Improve the quality of outputs }\end{array}$ \\
\hline & & $\begin{array}{l}\text { External Organizational } \\
\text { Factors }\end{array}$ & $\begin{array}{l}\text { Changes in technologies, Access to new markets, Achieve to competi- } \\
\text { tors, Responsiveness to changing customer needs }\end{array}$ \\
\hline Jafar Razmi (2010) & Iran (Tehran) & None & Management, Strategy, Quality, Technology, Costs, risk taking \\
\hline
\end{tabular}

study showed that the 22 sub-criteria are more important in decision making for outsourcing health services (Table 3).

\begin{tabular}{lcl} 
Table 2. Experts' panel results \\
\hline Factors & Sub-Factors \\
\hline Strategic & 1 & Focus on core function \\
& 2 & Access to World-Class capabilities \\
& 3 & Freeing resources for core activities \\
& 4 & Accelerate re-engineering benefits \\
& 5 & Improve flexibility versus change \\
& 6 & Risk sharing \\
& 7 & Regulations governing \\
Quality & 1 & Improve service quality \\
& 2 & Procure higher reliability and competency \\
Management & 1 & Save the management time \\
& 2 & Reduce the management load \\
& 3 & Increase the speed of implementation \\
& 4 & Improve Safety management \\
& 5 & Improve accountability \\
& 6 & Need specialized management \\
& 7 & Function difficult to manage \\
& 1 & Achieve flexibility with changing tech- \\
& & nology \\
& 2 & Achieve innovative ideas \\
& 3 & Acquire new skills or technical knowledge \\
\hline
\end{tabular}

\section{Discussion}

One of the main challenges facing senior healthcare administrators is to determine the service capable of outsourcing. Therefore before deciding to outsource services, it is necessary to investigate effective criteria. Because the effective criteria for outsourcing decision-making evaluate the organization's performance and help the organization to select the option of outsourcing or non-outsourcing (25). The purpose of this study was to identify effective criteria for decision making for outsourcing of healthcare services. The results of the study showed that outsource healthcare services is based on a multi-criteria decision.

\begin{tabular}{lll} 
Table 2. Cntd & & \\
\hline Function & 1 & Complexity of function \\
characteristics & 2 & Function integration and structure \\
& 3 & Function difficult to control \\
Economic & 1 & Save the overall cost \\
& 2 & Reduce the labor and operating cost \\
& 3 & Make the fixed costs into variable costs \\
& 4 & Improve the cash flow \\
& 5 & Cash infusion \\
& 6 & Reduce capital costs \\
& 7 & Increase the economic efficiency \\
\hline
\end{tabular}


Table 3. Factors influencing decision making for health services outsourcing

\begin{tabular}{ll}
\hline Factors & Sub-Factors \\
\hline Strategic & Focus on core function \\
& Freeing resources for core activities \\
& Improve flexibility versus change \\
& Risk sharing \\
& Regulations governing \\
Economic & Save the overall cost \\
& Reduce the labor and operating cost \\
& Make the fixed costs into variable costs \\
& Cash infusion \\
& Reduce capital costs \\
& Increase the economic efficiency \\
& Improve service quality \\
Quality & Procure higher reliability and competency \\
& Save the management time \\
Management & Reduce the management load \\
& Increase the speed of implementation \\
& Improve Safety management \\
& Improve accountability \\
& Need specialized management \\
& Function difficult to manage \\
& Achieve innovative ideas \\
Acquire new skills or technical knowledge
\end{tabular}

According to these results, when deciding on the outsourcing of healthcare services, we must consider the criteria such as strategy, quality, management, technology, and economics. We will continue to discuss these factors.

Strategy: The outsourcing strategy criterion enables the organization to gain more advantages due to long-term goals. The results of this study showed that focusing on the main activity, the release of resources for the main activity, the improvement of flexibility versus change, risk sharing, and law supervision, are strategic issues affecting outsourcing decision making. The main drivers of outsourcing have changed from economic issues to strategic issues because strategy incentives allow the organization to focus on core capabilities and activities. On the other hand, due to competition, organizations have been forced to direct domestic scarce resources to major activities with more effectiveness $(18,19)$. Another strategy issue that encourages outsourcing is flexibility which is defined as the ability to respond to changes in the least amount of cost, time, effort and performance. Moreover flexibility is a significant source of competitive advantage (26). Kremic points out that organizations need to be flexible and responsive to changeable customers' needs, which can be facilitated through outsourcing (19). Of course, it should be noted that flexibility can have positive and negative concurrent effects in outsourcing decisions. Outsourcing May reduces risk to the organization by sharing the risk with providers. Also, before conducting a negotiation, health managers should carefully review their regulatory and supervisory implications (27).

Economic: Most studies have stated achieving cost savings of the organization as the main reason for the decision to outsource activities $(7-9,25)$. Organizations need a competitive strategy to achieve cost savings. An organization can achieve cost savings through principled outsourcing $(25,28)$. The key driver for most outsourcing decisions is to reduce the costs of manpower, materials, and resources. An activity is outsourced when expected costs as the result of outsourcing are less than the cost of doing it within the organization. In other words, increasing the cost of an activity in an organization increases the likelihood of outsourcing compared to the expected cost of outsourcing. Outsourcing helps the organization fixed costs, such as manpower costs and infrastructure costs into variable costs (28). When the labor force is reduced through outsourcing, less infrastructure and support systems are needed. Therefore, through outsourcing, funds are injected into the organization and the cash flow of money improves in the organization. The necessity of investing in core activities makes the organization willing to select outsourcing and reduce the capital budget in noncore activities $(5,28)$.

Although organizations may outsource their activities for economic reasons, there is no guarantee that expected savings will occur (19). Some evidence suggests that the estimated cost savings have not been achieved. For example, findings of Ferdosi et al. indicate that after outsourcing, the final cost of each hospital bed and, ultimately, the total cost has increased (29). Also, some indirect costs such as contract costs, contract control, morale ignoring, absence of work, and efficiency may be added less by outsourcing (19).

Quality: One of the goals of most organizations from outsourcing is a quality improvement $(30,31)$. In this regard, in the health sector, the main goal of outsourcing activities, is to promote the quality and service productivity by focusing on the main activities and patients. The results of Akbulut's research showed that outsourcing in $38.8 \%$ of studies was effective on improving the quality of services and also in $27.7 \%$ of studies on productivity and efficacy increase (8). One of the factors affecting the effectiveness and efficiency of outsourcing strategy is the monitoring of the quality of service outsourced. Therefore, to ensure the maintenance and upgrading the quality of outsourced services, consideration of monitoring and control mechanisms are essential (29). Increasing the quality of service can lead to trust and merit in the organization, reduced costs, and increased consumer satisfaction (28, 30 ).

Management: The criterion of management is factors that affect performance and service management. In the present study, the management criterion for outsourcing decision making for health services included 7 subcriteria. These sub-criteria were: saving time management, reducing management workload, increasing the speed of implementation, improving safety management, improving accountability, the need for specialized management and the function difficult to manage. These criteria are consistent with the results of the Al-Nehmi study (28). Mehdizadeh et al. have highlighted the speed increase in services provided to patients as one of the outsourcing benefits of hospitals (32). For each organization, reducing the time spent doing an activity is an important goal. Outsourcing services can be a good strategy to achieve this goal. As outsourcing subsidiary services, the organization can focus on its core activities (28). Hsiao et al. also suggested that outsourcing could help reduce workload and maintain personnel energy and hospital management (12). 
The need for specialized management refers to the skills of the staff and top managers in the organization, which influences on outsourcing decision. The lack of skilled and specialized people to manage activities in organizations is one of the reasons for outsourcing. As a result, in some circumstances, external contractors are selected to manage and provide appropriate services due to having sufficient manpower (28). Sometimes the difficulty of managing a service or activity cause it to be outsourced. The difficulty in managing an activity can be due to its characteristics and organizational shortcomings, such as technical manpower $(19,20)$.

Technology: One of the main reasons for outsourcing is access to key technologies $(15,33)$. Through outsourcing, the organization can work to acquire new skills and knowledge and develop its expertise in maintaining highlevel technologies (28). One of the benefits of outsourcing to health systems is the use of modern medical and diagnostic equipment (32). Outsourcing enables healthcare systems to immediate implementation of the medical reprocess program without capital investment $(12,27)$. The results of this study showed that in the field of technology, two criteria of access to innovative ideas and techniques, and the acquisition of new skills or technical knowledge are influential on decision making for outsourcing of health services in Iran. At the time of decision making for outsourcing, it seems that increasing the organization's ability to utilize technical skills and knowledge, as well as new ideas, are considered by managers.

One of the factors influencing outsourcing decision making is the function characteristics, which was excluded from this study according to experts' opinions. This could indicate that at most of the times, managers outsource justify cost cutting and improved quality, but do not pay attention to the characteristics of the service or function. Evidence suggests that outsourcing of nonclinical services has been successful, but outsourcing of clinical services has been accompanied by risks (7). This can be due to specific service features that should be taken into account when deciding on outsourcing. In fact, the main problem for managers in outsourcing is to identify the services that need to be outsourced (7). For example, Kavosi et al. showed that according to the service characteristic, the tendency to outsource laboratory and radiology units should be low, while hospital managers had a great desire to outsource these units (2). Therefore, the failure of managers to pay attention to the characteristics of services during outsourcing decisions can lead to errors in decision making. It seems that outsourcing managers and experts in the healthcare system of Iran do not pay enough attention to the role and importance of the function characteristics factor in outsourcing decision making. Therefore, the importance and impact of this important factor must be clear and transparent to them.

\section{Conclusion}

This research has provided effective criteria to support decision making on outsourcing healthcare services. The study showed that the decision to outsource healthcare services was a complex and multi-criteria decision. There- fore, when deciding on outsourcing health services, attention should be paid to various factors. The findings of this study can help to make the right decision for outsourcing health services.

\section{Limitation}

One of the limitations of this study was the lack of access to some of the experts in the Delphi process. To remove this limitation, questionnaires were sent to them by email. Also, lack of determining the weight (effectiveness rate) of factors in outsourcing decision making was other limitation of this study, which can be investigated in subsequent studies.

\section{Acknowledgment}

The present article was extracted from the thesis written by Saeideh Khanian and financially supported by Shiraz University of Medical Sciences (grants No. 7338).

\section{Conflict of Interests}

The authors declare that they have no competing interests.

\section{References}

1. Masoumpour SM, Rahimi SH, Kharazmi E, Kavousi Z, Mosalah NH, Abedi Z. Assessing waiting time in emergency department of Shahid Faghihi hospital, Shiraz and presenting appropriate strategies using quality function deployment (QFD) method, 2011-2012. HAKIM. 2013;16(2):159-68

2. Kavousi Z, Setoudehzade F, Kharazmi E, Khabiri R, Ravangard R, Rahimi H. The level of propensity to outsource Study: Based on hospital services features by managers and staff perspective in hospitals of Shiraz University of Medical Science, 2010. Journal of Hospital. 2012;11(1):9-18.

3. Kahouei M, Farrokhi M, Abadi ZN, Karimi A. Concerns and hopes about outsourcing decisions regarding health information management services at two teaching hospitals in Semnan, Iran. Health Inf Manage. 2016;45(1):36-44.

4. Maher A, Saadati A, Hosseini SM. Effect of Outsourced Pharmacies of Rural Healthcare Centers on Service Quality in Abharand Soltanieh Counties. Intel J Med Res Health Sci. 2016;5(5):164-9.

5. Paltriccia C, Tiacci L. Supplying networks in the healthcare sector: a new outsourcing model for materials management. Indust Manag Data Sys. 2016;116(8):1493-519.

6. Macinati MS. Outsourcing in the Italian National Health Service: findings from a national survey. Int $\mathrm{J}$ Health Plann Manage. 2008;23(1):21-36.

7. Hayati R, Setoodehzadeh F, Heydarvand S, Khammarnia M, Ravangard R, Sadeghi A, et al. The decision-making matrix of propensity to outsourcing hospital services in Bandar Abbas, Iran. J Pakistan Med Assoc.. 2015;65(12):1288-94.

8. Akbulut Y, Terekli G, Yıldırım T. Outsourcing in Turkish Hospitals: A Systematic Review. Ankara Sağlık Hizmetleri Dergisi. 2013;11(2):25-33.

9. Tynkkynen L-K, Lehto J, Miettinen S. Framing the decision to contract out elderly care and primary health care services-perspectives of local level politicians and civil servants in Finland. BMC Health Serv Res. 2012;12(1):201.

10. Ikediashi D, Ekanem AM. Outsourcing of facilities management (FM) services in public hospitals: a study on Nigeria's perspective. Journal of Facilities Management. 2015;13(1):85-102.

11. Young S, Macinati MS. Health Outsourcing/Backsourcing: Case studies in the Australian and Italian health sector. Public Management Review. 2012;14(6):771-94.

12. Hsiao C-T, Pai J-Y, Chiu H. The study on the outsourcing of Taiwan's hospitals: a questionnaire survey research. BMC Health Serv Res. 2009;9(1):78.

13. Torani S, Maleki M, GhodosiMoghadam S, Gohari M. Comparison of Efficiency \& Effectiveness of Firozgar education Drugstore before $\&$ after of Outsourcing. Health Management. 2009;12(38):59-72. 
14. Mousavi H, Khodamoradi F, Zarinabadi CHR, Saadati HM, Mohammadi M, Mahboubi M, et al. The effect of radiology services outsourcing on patients' satisfaction in Tehran city hospitals. J Med Life. 2015;8(Spec Iss 3):31.

15. Karimi S, Agharahimi Z, Yaghoubi M. Impacts of outsourcing in educational hospitals in Iran: A study on Isfahan University of Medical Sciences-2010. J Educ Health Promot. 2012;1.

16. Schniederjans MJ. Focused issue on operations research and outsourcing. Computers \& Operations Research. 2007;34(12):3515.

17. Tajdini S, Nazari M. IS outsourcing decision: A quantitative approach. International Journal of Business and Management. 2012;7(2):113.

18. Hassanain MA, Assaf S, Al-Hammad AM, Al-Nehmi A. A multicriteria decision making model for outsourcing maintenance services. Facilities. 2015;33(3/4):229-44.

19. Kremic T, Icmeli Tukel O, Rom WO. Outsourcing decision support: a survey of benefits, risks, and decision factors. Supply Chain Management: an international journal. 2006;11(6):467-82.

20. Assaf S, Hassanain MA, Al-Hammad AM, Al-Nehmi A. Factors affecting outsourcing decisions of maintenance services in Saudi Arabian universities. Property Management. 2011;29(2):195-212.

21. Mehrdad R. Health system in Iran. Intl Med Commun J. 2009;52(1):69-73.

22. Jahanmehr N, Rashidian A, Khosravi A, Farzadfar F, Shariati M, Majdzadeh R, et al. A conceptual framework for evaluation of public health and primary care system performance in Iran. Glob J Health Sci. 2015;7(4):341.

23. Rahimi H, Kavosi Z, Shojaei P, Kharazmi E. Key performance indicators in hospital based on balanced scorecard model. J Health Manag Informatic. 2016;4(1):17-24.

24. Lakke SE, Wittink H, Geertzen JH, van der Schans CP, Reneman MF. Factors that affect functional capacity in patients with musculoskeletal pain: a Delphi study among scientists, clinicians, and patients. Arch Phys Med Rehabil. 2012;93(3):446-57.

25. Salla N, Juga J, Oikarinen E, Liisa FM. Outsourcing decisionmaking in mining industry. unpublished master thesis, Oulu Business School, Oulu University. 2013.

26. Scherrer-Rathje M, Deflorin P, Anand G. Manufacturing flexibility through outsourcing: effects of contingencies. International Journal of Operations \& Production Management. 2014;34(9):1210-42.

27. Liu X, Hotchkiss DR, Bose S. The effectiveness of contracting-out primary health care services in developing countries: a review of the evidence. Health policy plan. 2007;23(1):1-13.

28. Al-Nehmi A. Decision Factors for Outsourcing the Maintenance Services of Saudi Universities: King Fahd University of Petroleum and Minerals; 2009.

29. Ferdosi M, Farahabadi E, Mofid M, Rejalian F, Haghighat M, Naghdi P. Evaluation of Outsourcing in Nursing Services: A Case Study of Kashani Hospital, Isfahan in 2011. Mater Sociomed. 2013;25(1):37.

30. Oduk PM. Factors influencing outsourcing at kenya union of savings and credit cooperatives. IJBC. 2013;3(1):83-99.

31. Foxx WK, Bunn MD, McCay V. Outsourcing services in the healthcare sector. Journal of Medical Marketing. 2009;9(1):41-55.

32. Mehdizadeh P, Dopeykar N, Gol-Alizadeh E, Yaghoubi M. The Status of Outsourcing Services in a Specialized Tehran Hospital Using SWOT. Hospit Pract Res. 2016;1(3):95-9.

33. Chen H, Chen TJ. Asymmetric strategic alliances: A network view. J Busi Res. 2002;55(12):1007-13. 